\title{
Metaphor Analysis in Political Discourse Based on Discourse Dynamics Framework for Metaphor: A Case Study*
}

\author{
Chunfang Huang \\ Southwest University of Political Science and Law, Chongqing, China
}

\begin{abstract}
Contrary to the pre-existing mapping and top-down instantiation from thought to language, Discourse Dynamics Framework for Metaphor(DDFM)argues that metaphor works mainly inductively upwards from the linguistic metaphor data, offering a tool for understanding people, revealing something of speaker's ideas, affective aspects and values. This study is designed to apply DDFM to a political speech about fighting COVID-19 made by Xi Jinping, the president of the People's Republic of China. Assisted by computer software, such as tables of Microsoft Office, to sort metaphors of each segment of this speech, this article investigates metaphors in the speech by progressive process of metaphor analysis of DDFM. It is found that: (1)The most frequently occurring metaphors are related to bodily action and body experience, which implies actions Chinese government will take.(2)The dynamically emergent systematic metaphors evolve as the discourse proceeds, conveying the political ideas and attitudes of Chinese government in fighting COVID-19.(3) Most of metaphors are conventionalized, which indicates the framing role of conventional metaphors in discourse. Thus, DDFM offers a new approach regarding metaphors in political discourse.
\end{abstract}

Index Terms—political discourse, Discourse Dynamics Framework for Metaphor(DDFM), metaphor vehicle, systematic metaphor

\section{INTRODUCTION}

Dynamic Systems Theory (DST), developed as a branch of mathematics, refers to systems that change with time. It has the following features: interconnectedness, non-linearity, dynamics and self-organization. That is, all variables are interconnected, and changes in one variable will influence all other variables that are part of the system. Systems are constantly developing through interaction with their environment and through internal self-organization. LarsenFreeman (1997) first applied DST to second language acquisition (SLA). De Bot et al. (2007) conducted further study on SLA from the perspective of DST. According to them, language can be seen as a dynamic system, and language development shows some of the core features of dynamic systems.

Cameron applied DST to metaphor in discourse and established a discourse dynamics framework for metaphor (DDFM) (Cameron, 2010). DDFM focuses on metaphor in language use in discourse, explaining how metaphor conveys people's feelings, attitudes and conceptualizations. This paradigm of metaphor research based on DST has been applied to education discourse, reconciliation discourse and medicine discourse and so forth (Cameron et al, 2009, 2014; Ritchie and Cameron, 2014; Semino et al, 2014). In China, this theory was introduced and interpreted by some researchers (Cheng, 2015; Shan, 2019; Sun et al., 2017) but little attention has ever been paid to applying this theory to political discourse.

Political discourse is a form of discourse produced in institutional settings, such as government reports, parliamentary debates, party programs, governmental documents, political speeches and so on (Van Dijk, 2002).Metaphor in political discourse not only constructs politics but also is the core of political analysis and policymaking (Beer \& De Landstheer, 2004), contributing to interpreting complicated political ideas, arousing people's emotions and showing particular political intentions(Wilson, 1990). DDFM offers a new approach to analyzing linguistic metaphors in political discourse, revealing speakers' ideas, attitudes and values through the prism of the discourse event in which they are expressed. The current article applies DDFM to metaphors in the speech made by $\mathrm{Xi}$ Jinping, the president of China.

\section{CORE FEATURES OF Discourse DyNAMICS FRAMEWORK FOR METAPHOR (DDFM)}

Though inspired by conceptual metaphor (proposed by Lakoff \& Johnson, 1980), DDFM does not formulate metaphor in terms of highly generalized and abstract conceptual domains, but argues that metaphor works mainly inductively upwards from the linguistic metaphor data. It is mainly characterized by the following.

\footnotetext{
* This article was supported by Chongqing Federation of Social Science Circles under Grant 2019YBYY 136; and Chongqing Municipal Education Commission under Grant yjg 193049.
} 


\section{A. Interconnectedness of Dimensions of Metaphor}

There are various dimensions of metaphor use in discourse: linguistic, embodied, cognitive, affective, sociocultural. These dimensions are interconnected. A linguistic metaphor is related to a network of ideas, conceptual and affective patterns which are interwoven with correlates from people's bodily actions and embodied experience (Cameron, 2010). And it indicates socio-cultural aspects in which people are involved and reveals speaker's evaluations, attitudes or emotions, perspectives or beliefs, and values.

\section{B. Systematicity of Metaphor Use}

At the micro level, the metaphorically used words or phrases, which are called metaphor vehicles (Cameron, 2010), are grouped together based on the similar semantics of their basic meaning. At the macro level, an emergent group of closely connected metaphor vehicles forms systematic metaphor, which is a kind of temporary stabilization established to build up topic-vehicle connections, revealing speakers' ideas, attitudes and values. According to Cameron et al. (2010), systematic metaphor includes metaphor framing and metaphor scenarios/stories. Metaphor framing is the frame of discourse, and metaphor scenario enables the speaker to draw on metaphors to build narrative frames for conceptualization and assessment of socio-political issues (Musolff, 2006). Thus, a metaphor scenario can be regarded as the combination of some sort of event with a set of conventional expectations, attitudes and evaluations (Cameron et al, 2010).

\section{Dynamic Discourse and Dynamic Metaphor}

In DDFM, it is argued that linguistic and cognitive phenomena in discourse are understood as processes, flows or movement, rather than objects. On the one hand, discourse is seen as a dynamic system, adapting and flowing as speakers develop their own or other people's ideas. On the other hand, as discourse continues, linguistic metaphors shifting, which includes vehicle repetition, vehicle relexicalization, vehicle explication, vehicle contrast (Cameron, 2010), occurs. It drives the system dynamics and leads to the emergence of systematic metaphors. With the changes of topic, systematic metaphor also evolves. Thus, linguistic metaphors, discourse participants' emotions, attitudes, ideas are emergent in the dynamic flux of discourse.

\section{Progressive Process of Metaphor Analysis}

Metaphor analysis progressively follows the following procedure. Firstly, metaphors are identified. The method for identifying metaphor is developed by MIP (metaphor identification procedure) (Pragglejaz group, 2007). This differs from the quantitative corpus-based method of using concordance keywords from the source domain (CharterisBlack, 2004). In MIP, each candidate metaphor is checked for: (1) looking up the lexical unit (words or phrases) in a dictionary for its more basic meaning - in this sense, the basic meaning tends to be more concrete (related to human beings' intuitive senses: of imagining, seeing, hearing, feeling, smelling, and tasting), related to bodily action, more precise, historically older; (2) its meaning in the discourse context; (3) an incongruity or contrast between the basic meaning and contextual meaning, and a transfer from the basic to the contextual meaning. If the lexical unit meets each of the above, it is coded as metaphor vehicle (Cameron \& Maslen, 2010). Secondly, metaphor vehicles are grouped on the basis of the semantics of their basic meaning. Grouping metaphor vehicles is interpretive. This process depends upon a combination of analytical rigor and creativity, which is called "principled flexibility" by Cameron. Thirdly, systematic metaphors are constructed by the analyst by collecting all the linguistic metaphors related to a particular topic within each vehicle grouping. A systematic metaphor emerging in a discourse event can become the starting point for further investigation and analysis, in turn revealing its implications for research aim (Cameron et al., 2010). Finally, the researcher interprets the function of metaphor by integrating metaphor analysis with analys is of discourse activity. This framework of DDFM is displayed in the following figure.

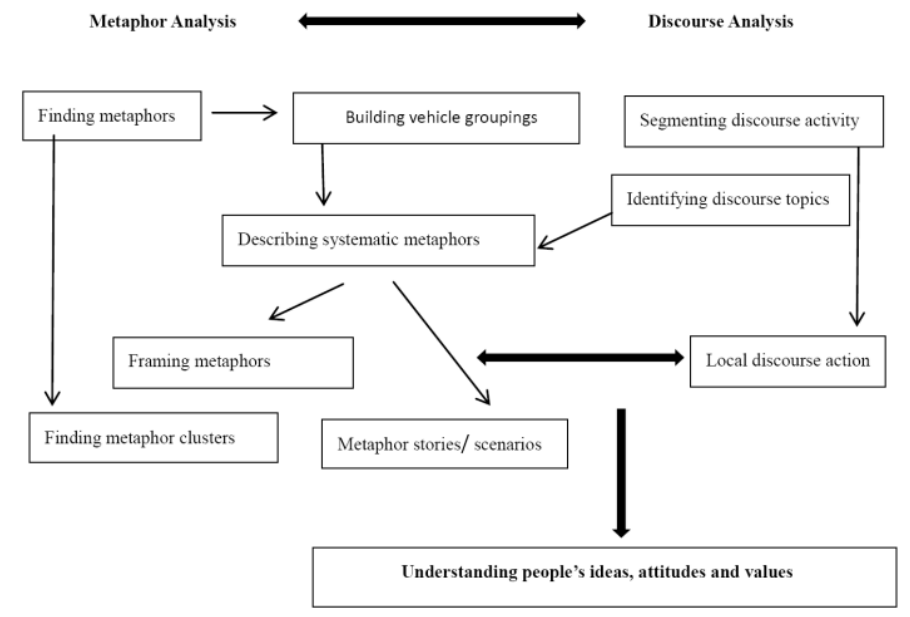

Figure 1. Metaphor-led discourse analysis (Cameron, 2010, p.147) 
Note: Two types of metaphor patterns emerge in discourse: systematic metaphor (semantic) and metaphor cluster (distributional). Metaphor cluster often occurs in the conversation (Cameron, 2010). Thus, this paper will not discuss cluster.

The framework of DDFM is applied to this research to sate that: (1) Investigating the metaphors in political discourse from a dynamic perspective can describe and explain the nature of metaphor in use in discourse. (2) By studying the frequency of metaphor vehicles and the dynamics of metaphor emergence in political discourse, this research explains the topic-metaphor interconnectedness, inferring the ideas, attitudes and values of speaker of this discourse.

\section{METHODOLOGY}

\section{A. Research Questions}

At the critical moment of fighting COVID-19, Xi Jinping, the president of China, made a speech on Feb. 5, 2020 when presiding over the third meeting of the Commission for Overall Law-based Governance of the CPC Central Committee $^{1}$ (referred to as "Xi's speech"). Xi's speech contains many metaphors ${ }^{2}$. And a variety of metaphor vehicles are interwoven throughout the speech. The current article applies DDFM to metaphors in this political speech, trying to answer the following questions: 1) what type of metaphors do occur most frequently? 2) How do the metaphors reveal the Chinese government's political attitude and ideas to carry out law-based epidemic prevention and control, to implement judicial reforms and to advance overall-based governance?

\section{B. Research Object}

In order to describe discourse activity and analyze metaphors in discourse, segmenting discourse is necessary. Discourse is usually segmented by its boundaries that mark a change from one activity to another. The boundaries have the following language features: change of a paragraph in written text or a pause in talk, discourse markers, changes in topic, changes in lexis, changes in grammar (Cameron, 2010). Xi's speech is considered as a written political discourse prepared for oral delivery. It mainly has 7 paragraphs. In this article, Xi's speech is segmented on the basis of changes in topics. It is divided into five segments: (i) preamble of this speech, (ii) legal documents approved by the commission, (iii) practicing law-based epidemic prevention and control of COVID-19, (iv) implementing judicial reforms, (v) carrying out overall law-based governance of the country. Table 1 shows the segmentation of Xi's speech.

TABLE 1

DisCOURSE SEGMENTS IN XI'S SPEECH

\begin{tabular}{|l|c|l|}
\hline segment & paragraph & \multicolumn{1}{|c|}{ topic } \\
\hline segment 1 & 1 & preamble \\
\hline segment 2 & 2 & legal documents approved \\
\hline segment 3 & $3-5$ & epidemic prevention and control \\
\hline segment 4 & 6 & judicial reforms \\
\hline segment 5 & 7 & overall law-based governance \\
\hline
\end{tabular}

\section{Research Process}

In DDFM, metaphor analysis in discourse analysis activity is performed in a recursive process. That is, metaphor analysis in every segment follows the following procedure: identifying metaphor vehicle $\rightarrow$ finding patterns of use by grouping and labeling of metaphor vehicle $\rightarrow$ constructing systematic metaphor $\rightarrow$ revealing the function of metaphor in the production and interpretation of discourse. Every segment of Xi's speech is analyzed based on this procedure. The discussion in the following will move between metaphor and discourse activity, combining analyses of metaphors and discourse activity. Chinese words and phrases in quotation marks are from the text of Xi's speech.

\section{RESULTS AND ANALYSIS}

\section{A. Segment 1: Preamble (Paragraph 1)}

The first paragraph is the preamble of Xi's speech, telling the audience the purpose of the speech. In this paragraph, there are some metaphors describing the purpose. Firstly, on the basis of MIP, the following incongruous words or phrases are identified as metaphor vehicles: “第一位 di yi wei”, “依法防控 yi fa fang kong ”, “发力 fa li ”. “有力 you $\underline{l i}$ ”. The phrase, “第一位 di yi wei," (in the first place) has a basic meaning of location in an initial location, which is metaphorical when talking about events in time. LOCATION metaphor is constructed, which is used to talk about the importance of people's safety and health. And in the phrase, “依法防控 yi fa fang kong ” (carry out law-based

\footnotetext{
${ }^{1}$ The transcript was published on CCTV website: http://news.cri.cn/20200205/45fdbfef-13cb-78fb-2f44-1e43dfbad52c.html

${ }^{2}$ In this article, based on DDFM, metaphor vehicles are identified on the basis of MIP (metaphor identification procedure) (Pragglejaz group, 2007). They are not completely the same as the traditional "conceptual metaphor" proposed by Lakoff and Johnson.
} 
epidemic prevention and control), SUPPORT metaphor ${ }^{3}$ and CONTROL metaphor, which are related to bodily action, are used. The word, “依 yi" (support), has the basic meaning of "rest oneself against something", which is metaphorical when talking about "law-based". Another word, "控 kong" (control) has the basic meaning of "in the palm of one's hand", which is metaphorical when talking about epidemic control. The words, “发力 fa li", “有力 you li” (powerful) are used to discuss the greater efforts for strengthening legislation, judiciary, law enforcement and rule of law connected with the epidemic prevention and control. These words related to bodily experience have the basic meaning of "physical, muscular capacity to exert force on objects". This meaning is incongruous in this context of law. Its contextual meaning is "make something powerful". The vehicle term “力 li" (powerful) related to this topic is repeatedly used to construct systematic STRENGTH metaphor.

In this part, the above metaphors are used to imply the purpose of the speech: fighting COVID-19, people's safety and health should be placed in the first priority. And we must endeavor to do everything to control the epidemic in accordance with law.

\section{B. Segment 2: Legal Documents Approved (Paragraph 2)}

In paragraph 2 of the speech, JOURNEY metaphor is used to indicate that some legal documents are approved by the commission. The word, “通过 tong guo" (pass) has the basic meaning of going through, which is metaphorical when used to talk about documents approved by quorum, the majority of persons attending the meeting.

\section{Segment 3: Epidemic Prevention and Control (Paragraphs 3-5)}

Paragraph 3 is a brief bridging passage. At the critical moment of preventing and controlling COVID-19, it is essential to make efforts to strengthen greater legislation, law enforcement, judicial and law observance. Some metaphorically used words or phrases are used to make a description and interpretation. On the basis of MIP, the following incongruous words or phrases are identified as metaphor vehicles: “轨道 gui dao”, “推进 tui jin”. But, all work involved in epidemic prevention and control must be carried out in a law-based manner. In building up this topic-vehicle connection, metaphorical expression about rule of law is “法治轨道 fa zhi gui dao” (on the way of 'rule of law'). The word, “轨道 gui dao" (path) has the basic meaning of a track made by people walking over the ground, which is metaphorical when talking about the process of rule of law, constructing JOURNEY metaphor. And the metaphor about carrying forward the work is “推进...工作 tui jin ...gong zuo" (advance ... work). The basic meaning of "推进 tui jin" (advance) is "to move forward physically". But when the basic meaning is transferred to the contextual meaning of boosting fight against COVID-19, it is metaphorical. MOVEMENT metaphor is constructed to indicate carrying forward all the epidemic prevention and control work.

Paragraph 4 is about the specific measures taken in carrying out law-based epidemic prevention and control. Some systematic metaphors are constructed to describe the legislation, law enforcement, judicial and law observance. They are shown in the following table.

TABLE 2

THE SYSTEMATIC METAPHORS IN PARAGRAPH 4

\begin{tabular}{|l|l|l|}
\hline \multicolumn{1}{|c|}{ text } & \multicolumn{1}{|c|}{ topic } & \multicolumn{1}{c|}{ systematic metaphor } \\
\hline sentence 1 & legislation & BUILDING, SYSTEM \\
\hline sentences 2-4 & law enforcement & STRENGTH, PHYSICAL ACTION, ENFORCEMENT \\
\hline Sentences 5-9 & law observance & SUPPORT, STRENGTH \\
\hline
\end{tabular}

In the first sentence of this segment, two metaphors about legislation (BUILDING metaphor and SYSTEM metaphor) emerge. On the basis of MIP, the words, “建设 jian she” “构建 gou jian”(build ) have the basic meaning of making structure by putting pieces together, which are metaphorical when talking about legal system. Their basic meaning is transferred to contextual meaning. These two relexicalized metaphor vehicles are connected with the topic of legislation. They are used to construct systematic BUILDING metaphor. This systematic metaphor is used to describe the establishment of legal system. The word, “体系 ti xi” (system) has the basic meaning of natural organization (e.g., biological system). It is metaphorically used (SYSTEM metaphor) when talking about the legal system. These metaphors emergent in the discourse flux function together, combining the discourse event with the speaker's idea, which has the connotation that a legal system must be established in order to improve the legislation on epidemic prevention and control.

In sentences 2 through 4 of this segment, some metaphors are used to talk about law enforcement. Firstly, in the

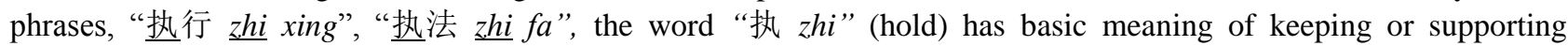
something by using hands or arms. It is metaphorical when used in the context of law enforcement. The vehicle term “执 zhi” (hold) is repeated in this segment to construct systematic ENFORCEMENT metaphor to talk about law enforcement. Then, the words, “加强 jia qiang” (strengthen), “加大 jia da” (strengthen), “力度 $l i d u$ ” (strength) are

\footnotetext{
${ }^{3}$ In this article, SUPPORT, CONTROL, BUILDING, ENFORCEMENT, MOVEMENT, SAFEGUARD metaphor etc. are defined as the submetaphors of PHYSICAL ATION metaphor.
} 
used in the context of law enforcement. Their basic meaning of "exerting physical force on objects" is transferred to contextual meaning of "making something powerful". These near synonymous or equivalent metaphor vehicles developed by vehicle relexicalization are repeatedly used to construct systematic STRENGTH metaphors, revealing the idea of forceful law enforcement. Finally, systematic PHYSICAL ACTION ${ }^{3}$ metaphors are used to describe the action taken in the process of law enforcement. The word, “监管 jian guan” (supervise), has the basic meaning of keeping watch over something. The word, “打击 $d a j i$ ” (beat), has the basic meaning of hitting something again and again. In the phrase, “实施 shi shi” (carry out) has the basic meaning of holding in arms or on back while moving. And the phrase, “查处 cha chu” (look into and punish), “查 cha” (look into) has the basic meaning related to human beings' intuitive sense of seeing. The above words or phrases have the basic meanings related to human beings' intuitive senses or bodily actions. This particular set of linguistic metaphor vehicles are used to talk about the specific actions in the process of law enforcement and construct systematic PHYSICAL ACTION metaphors. The above systematic metaphors in this discourse segment convey the speaker's political attitude: calling for greater law enforcement efforts, taking a variety of actions to perform the work of epidemic prevention and control.

In sentences 5 through 9 of this segment, some metaphors about law observance are emergent. These metaphors are SUPPORT metaphor, STRENGTH metaphor. Then what should be done to carry out law observance? The systematic CONTROL metaphor and some other PHYSICAL ACTION metaphors are used. The metaphorically used words or phrases are “防控, fang kong”, “履行 lü xing” (perform), “运用 yun yong” (use), “推进 tui jin” (advance),“提高 ti gao”(lift),“保障 bao zhang”(safeguard). The basic meanings of these metaphor vehicles are connected with bodily action and physical experience. These systematic metaphors are constructed to express the idea that in the process of preventing and controlling COVID-19, law observance is a necessity. Every forceful action must be taken in accordance with the law and various capacities must be strengthened to fight against the epidemic.

In this segment, with regard to the topic of "carrying out law-based epidemic prevention and control", the metaphor vehicle, “防控 fang kong” is used repeatedly for many times, constructing the systematic CONTROL metaphor. The metaphor vehicle, “依法 $y i f a$ ” is repeated for many times, constructing systematic SUPPORT metaphor. And the systematic PHYSICAL ACTION metaphor, STRENGTH metaphor, BUILDING metaphor and SYSTEM metaphor are constructed respectively by near synonym or equivalent metaphor vehicles. All these systematic metaphors are used to build up topic-vehicle connections, which have the potential to reveal Chinese government's positive and emphatic attitude and its determination to prevent and control the epidemic. Then, what to do? Measures must be taken from the following aspects: of the legislation, of law enforcement, of judicial and law observance so that all the work can be carried out in a law-based and orderly manner.

\section{Segment 4: Judicial Reform (Paragraph 6)}

This segment is about implementation of judicial reforms, rule of law in rural areas and the system reform of administrative reconsideration. The metaphor vehicles, “体制 $t i z h i$ ”, “制 zhi ”, “制度 $z h i d u$, are used to construct SYSTEM metaphor about the judicial system. The vehicle term, “改革 gai ge” (reform) has the etymologically basic meaning of "physically made again", transferred to its contextual meaning "having had a change of character". It constructs PHYSICAL ACTION metaphor about judicial reform. The metaphor vehicles, “加强 jia qiang ” (strengthen)(STRENGTH metaphor) and “推进 tui jin ”(advance) (MOVEMENT metaphor) are used to talk about what to be done to strengthen rule of law in rural areas. The word, “落实 luo shi (fulfil)" has the basic meaning of something physically falling on the ground, transferred to its contextual meaning "fulfil, carry out", constructing PHYSICAL ACTION metaphor to talk about the system reform of administrative reconsideration. The vehicle term, “推进 tui jin" is repeated to talk about the amendment of relevant legal rules. All the above linguistic metaphors in the trajectory of the speech are used to describe the reforms of judicial system and system of administrative reconsideration and work of strengthening rule of law in rural areas.

\section{E. Segment 5: Overall Law-Based Governance (Paragraph 7)}

In this paragraph, some metaphors about overall law-based governance are used. A lexical chain (repeated use of a word or connected word) emphasizes the metaphorical conceptualization of legal system: “国家治理体系 guo jia zhi li ti xi ” ( system of national governance), “法治体系fa zhi ti xi ” (system of rule of law), “国家治理制度化 guo jia zhi li zhi du hua " ( institutionalization of national governance), “法治保障制度 fa zhi bao zhang zhi du ” (system of legal safeguards), “法律服务体系 fa $l v f u$ wu $\underline{t i x i}$ ”( systematic SYSTEM metaphor, scattered about throughout this paragraph. In the discourse flux, the words, “推进 tui jin ”(advance), “跟进 gen jin” (follow up), “提高 ti gao” (lift ), “提升 ti sheng ”(lift) have the basic meanings of bodily movement, which are metaphorically used when talking about the work related to law-based governance, constructing systematic MOVEMENT metaphor. In this discourse segment, SYSTEM metaphor and MOVEMENT metaphor are built up to imply that overall law-based governance must go forward and make development. The metaphor vehicles, which are also used in segment 3, “加强 jia qiang”, “强化 qiang hua”, “增 强 zeng qiang " and “力度 $l i d u$ ” construct systematic STRENGTH metaphor. This reveals the attitude and 
determination of government and the greater efforts to be made by the government. All these metaphor scenarios contribute to revealing the political idea of the Chinese government. That is, law-based governance should be advanced to boost the role of rule of law in modernizing China's system and capacity for governance.

\section{DISCUSSION}

This political discourse analysis of Xi's Speech involved the segmentation of discourse in terms of the topics of the discourse. Bringing this together with patterns of metaphor use in this speech based on DDFM allows the following insights.

(1)The most frequently occurring metaphors are related to bodily action and body experience. By using the function of computer, the number of occurrences was counted. These metaphors include SUPPORT metaphors, CONTROL metaphor, STRENGTH metaphor, MOVEMENT metaphor. Their numbers of vehicle occurrences are 29, 24, 22 and 17 respectively (see table 3 ). And the SYSTEM metaphor is also frequently used. The number of vehicle occurrences is 19 (also see Table 3).

TABLE 3

Most FrequentLy OCCURRING Metaphors, With NuMBER OF VEHICLE OCCURRENCES

\begin{tabular}{|c|c|c|c|}
\hline systematic metaphor & metaphor vehicle & $\begin{array}{l}\text { metaphor shifting } \\
\text { (vehicle development) }\end{array}$ & $\begin{array}{l}\text { number of vehicle } \\
\text { occurrences }\end{array}$ \\
\hline SUPPORT & “依法 yi fa”( law-based) & vehicle repetition & 29 \\
\hline CONTROL & “防控 fang kong ”( prevention and control) & vehicle repetition & 24 \\
\hline STRENGTH & $\begin{array}{l}\text { “加强 jia qiang”, “强化 qiang hua”, “增 } \\
\text { 强 zeng qiang ”, “力度 li du”, “发力 } f a \\
l i \text { ”, “有力 you li ” (strengthen or } \\
\text { strength) }\end{array}$ & vehicle relexicalization & 22 \\
\hline SYSTEM & $\begin{array}{l}\text { “制度 } z h i d u \text { ”, “体制 } t i z h i \text { ”, “体系 } t i \\
x i \text { ”(system) }\end{array}$ & vehicle relexicalization & 19 \\
\hline MOVEMENT & $\begin{array}{l}\text { “推进 tui jin ”, “跟进 gen jin ”, “提高 } t i \\
\text { gao ”, “提升 ti sheng ”(move forward) }\end{array}$ & vehicle relexicalization & 17 \\
\hline
\end{tabular}

All the above systematic metaphors are interwoven and connected throughout Xi's speech. These metaphors interpret and construct political topics. These most frequently occurring metaphors in the trajectory of the speech construct a series of successively narrative metaphor scenario. That is SYSTEM $\rightarrow$ SUPPORT $\rightarrow$ CONTROL $\rightarrow$ STRENGTH $\rightarrow$ MOVEMENT. The linguistic, affective, socio-cultural variables of metaphor are interconnected, occurring in the speech. This scenario unveils the purpose of discourse activity. These systematic metaphors convey the political attitudes, ideas, imply actions Chinese government will take, and construct and highlight the rhetorical and conceptual structure of the speech.

(2) The discourse dynamics of this speech is followed by the dynamic metaphor emergence. This is especially highlighted in paragraph 4. In this paragraph, the unfolding of the dynamic system of discourse is led by the topic, "carrying out law-based epidemic prevention and control". The topic trajectory of the discourse is legislation $\rightarrow$ law enforcement $\rightarrow$ law observance. Linguistic metaphors followed by these topics are mapped onto the discourse. The trajectory of metaphors is as follow: BUILDING metaphor (legislation) $\rightarrow$ ENFORCEMENT metaphor (law enforcement) $\rightarrow$ SUPPORT metaphor (based on law) $\rightarrow$ STRENGTH metaphor (law observance with all one's strength) $\rightarrow$ other PHYSICAL ACTION metaphor (actions taken in the process of enforcing and observing law). So the dynamics of discourse activity is followed by different metaphor scenarios. Meanwhile, in this speech the dynamics of metaphor emergence is mostly embodied by vehicle repetition and vehicle relexicalization (see table 3 ). The vehicle terms are repeated and relexicalized to remain the same topic or move to connected topics of the speech. The dynamically emergent systematic metaphors evolve as the discourse proceeds. And they become the research tool of conveying the political ideas and attitudes of Chinese government in fighting COVID-19: calling for greater legislation, law enforcement, judicial and law observance efforts to strengthen the capacity to carry out law-based epidemic prevention and control and boost the role of rule of law in modernizing China's legal system.

(3) Most of metaphors in Xi's Speech are conventionalized. This indicates that conventional metaphor plays a framing role in discourse. Besides, most of these metaphorically used words are verbs because Xi's speech has language characteristics, such as frequently used imperative sentences and the present tense. Thus, the lexical choices, grammatical form and this kind of metaphorical pattern implies that now the Chinese government will carry out lawbased epidemic prevention and control in active and positive manner.

\section{CONCLUSION}

Based on DDFM, metaphor can be used as a research tool to investigate discourse data and to reveal something of people's ideas, attitudes and values. This paper innovatively applied DDFM to metaphor analysis of a political discourse -- Xi's speech. In Xi's speech, the evolution of metaphors is tracked. The metaphor vehicles are identified, grouped systematically with similar semantic characteristics, and examined in their discourse contexts. And the 
most frequently occurring systematic metaphors such as SUPPORT metaphor, CONTROL metaphor, STRENGTH metaphor, SYSTEM metaphor and MOVEMENT metaphor etc. are constructed to reveal the speaker's political ideas and attitudes: Chinese government will take some actions to carry out law-based epidemic prevention and control in active and positive manner, to strengthen reforms of judicial system and system of administrative reconsideration and to boost the role of rule of law in modernizing China's legal system. This research helps us understand how metaphors contribute to framing ideas and expressing attitudes and values in political discourse.

\section{REFERENCES}

[1] Beer, F. \& C. de Landstheer. (2004). Metaphor, politics, and world politics. In: Beer F and De Landtsheer C (eds.), Metaphorical World Politics. East Lansing: Michigan State, 5-52.

[2] Cameron, L. et al. (2009). The Discourse dynamics approach to metaphor and metaphor-led discourse analysis. Metaphor and Symbol, 2, 63-89.

[3] Cameron, L. (2010). The Discourse dynamics framework for metaphor. In L. Cameron \& R. Maslen (eds.), Metaphor analysis: Research practice in applied linguistics, social science and the humanities. London: Equinox Publishing Ltd, 77-94.

[4] Cameron, L \& R. Maslen. (2010). Identifying metaphors in discourse data. In L. Cameron \& R. Maslen (eds.), Metaphor Analysis: Research Practice in Applied Linguistics, Social Science and the Humanities. London: Equinox Publishing Ltd, $97-$ 115.

[5] Cameron, L., L. Graham \& R. Maslen. (2010). Finding systematicity in metaphor use. In L. Cameron \& R. Maslen (eds.), Metaphor analysis: Research practice in applied linguistics, social science and the humanities. London: Equinox Publishing Ltd, 116-146.

[6] Cameron, L. \& R. Maslen. (eds.) (2010). Metaphor analysis: Research practice in applied linguistics, social science and the humanities. London: Equinox Publishing Ltd.

[7] Cameron, L. et al. (2014). Metaphorizing violence in the UK and Brazil: a contrastive discourse dynamics study. Metaphor and Symbol, 1, 23-43.

[8] Charteris-Black, J. (2004). Corpus Approaches to Critical Metaphor Analysis. New York: Palgrave Macmillan.

[9] Cheng, L. (2015). A New Elucidation of Metaphor from the Perspective of Complex Dynamic Theory. Foreign Languages in China, 2, 39-46.

[10] de Bot, K., W. Lowie, \& M.Verspoor. (2007). A dynamic systems theory approach to second language acquisition. Bilingualism: Language and Cognition, 1, 7-21.

[11] Lakoff, G. \& M. Johnson. (1980). Metaphors we live by. Chicago, IL: University of Chicago Press.

[12] Larsen-Freeman, D. (1997). Chaos/complexity science and second language acquisition. Applied Linguistics, 2, 141-165.

[13] Pragglejaz Group. (2007).MIP: A method for identifying metaphorically-used words in discourse. Metaphor and Symbol, 1, 139.

[14] Ritchie, D. \& L. Cameron. (2014). Open hearts or smoke and mirrors: metaphorical framing and frame conflicts in a public meeting. Metaphor and Symbol, 3, 204-223.

[15] Shan, L.Y. (2019). On the use of complex systems theory in metaphor analysis: taking the dynamics approach to metaphor as an example. Foreign Language and Literature, 6, 93-100.

[16] Semino, E. et al. (2014). "Good" and "bad" deaths: Narratives and professional identities in interviews with hospice managers.Http://dis.sagepub.com/content/early/2014/07/03/1461445614538566 (accessed $20 / 5$ /2020).

[17] Sun, Y., Y.B. Qian \& T.Ma. (2017). Current status and development trends in metaphor studies. Modern Foreign Languages, 5 , 695-704.

[18] van Dijk, T. (2002). Political discourse and ideology. In Lorda, CU and M. Ribas (eds.), Anàlisi del discurs polític. Barcelona: Universitat Pompeu Fabra, 15-34.

[19] Wilson, J. (1990). Politically speaking: the Pragmatic Analysis of Political Language. Oxford: Blackwell.

Chunfang Huang is a full-time professor of Southwest University of Political Science and Law, an executive member of Association of Chinese Cognitive Translation. She was awarded Ph.D from Beijing Normal University and was a visiting scholar in Cambridge University, UK. Her research interests focus on discourse analysis, cognitive linguistics, legal language etc. She published more than 20 articles in journals such as Shanghai Journal of Translations, Foreign Language Research, Foreign Language and Literature etc., and 2 monographs. 